

\section{AKSELERERTE PASIENTFORLØP}

\section{Hvordan kan sykepleieren fremme pasientmedvirkning i postoperativ smertebehandling?}

Forfattere: Aud Karin Hjelpdahl Sjøveian og Marit Leegaard

\section{NøKKELORD}

- Kvalitativ studie

- Kirurgi

- Smerte

- Sykepleier-pasientforhold

- Spesialisthelsetjenesten

\section{INNLEDNING}

For pasienter med osteoartritt er protesekirurgi en anerkjent behandlingsmetode hvor målet er smertelindring, bedret funksjonsevne og livskvalitet (1). Inngrepet medfører sterke postoperative smerter, og opptreningen krever optimal smertebehandling $(2,3)$.

Konseptet Joint Care er siden 2008 blitt implementert ved tre norske helseforetak. Dette innebærer et akselerert pasientforløp ved hofte- og kneprotesekirurgi, hvor hensikten er å fremme effektivitet og kvalitet $\mathrm{i}$ alle ledd av behandlingskjeden $(4,5)$. Målet er å begrense den kirurgiske stressrespons, fremme tidlig mobilisering og gjenvinne normale kroppsfunksjoner. Behandling innebærer multimodale smertebehandlingsmetoder, tidlig peroralt inntak av ernæring og analgetika, og minimal bruk av katetre og dren $(6,7)$. Tett samarbeid mellom kirurger, anestesipersonell, sykepleiere og fysioterapeuter har stor betydning for optimal smertebehandling (8). Pasientens ressurser og rolle som deltaker i behandlingen er også sentral. Dette framheves gjennom preoperativ undervisning, fokus på gruppedynamikk mellom pasientene, og et kortvarig sykehusopphold (5).

\section{BAKGRUNN}

Et systematisk litteratursøk viste at forskning etter år 2000 innen akselererte pasientforløp, beskriver nye kirurgiske metoder, smertebehandlingsregimer, rehabilitering, kort hospitalisering, kostnadsreduksjon, samt den helsemessige gevinsten av behandlingen $(9,10)$. Danske studier viser at akselererte pasientforløp ved hofte- og kneprotesekirurgi har gitt positive økonomiske og helserelaterte resultater $(11,12,13)$, og gjennomsnittlig liggetid i sykehus er redusert fra 8,8 til 4,3 dager (14). Det er ikke funnet studier som belyser hvordan sykepleiere og pasienter samhandler om smertebehandlingen ved akselererte pasientforløp, og det er derfor tatt utgangspunkt $\mathrm{i}$ andre studier som peker på sentrale utfordringer ved postoperativ smertebehandling. En oversiktsartikkel (15) framhever at barrierer for effektiv smertebehandling kan ligge i oppfatninger og holdninger hos pasienter og sykepleiere, samt i sykepleiernes strukturering av arbeidstiden. Forskning viser også at mange sykepleiere og leger har manglende kunnskaper om konsekvensene av inadekvat smertebehandling (8). Fokus er blitt rettet mot å styrke sykepleiernes og pasientenes kunnskaper (15), og en godt evaluert intervensjon er planlagte preoperative undervisningsprogram ved elektiv kirurgi $(7,16)$.

Denne studien bygger på sykepleierens erfaringer fra et av landets helseforetak ett år etter at Joint Care ble implementert. Pasientgruppen i Joint Care-programmet har et alderspenn fra 45-80 år. Sammen med pårørende deltar pasientene på en felles forberedelsesdag, hvor de får undervisning

\section{Hva tilfører artikkelen?}

Studien belyser at akselererte pasientforløp ved protesekirurgi krever en aktiv kunnskapsoverføring fra sykepleier til pasient.

\section{Mer om forfatterne:}

Aud Karin Hjelpdahl Sjøveian er sykepleier med master i klinisk sykepleievitenskap og høgskolelektor ved institutt for helsefag, Høgskolen i Telemark. Marit Leegaard er anestesisykepleier, PhD og 1.-amanuensis ved institutt for sykepleie, Høgskolen i Oslo og Akershus. Kontaktperson: aud.sjoveiandahit.no. 
av sykepleier, ortoped og fysioterapeut. Sykepleier informerer om forventet postoperativ smerte og om bruk av "numeric rate scale» (NRS) som smertekartleggingsverktøy På en skala fra $0-10$, hvor $0=$ ingen smerte og $10=$ verst tenkelige smerte, angir pasienten et tall enten muntlig eller skriftlig, og målet er at NRS ikke overstiger 3 i hvile (17-19). Skalaen er et hjelpemiddel i dialogen mellom sykepleier og pasient, og angir pasientens subjektive smertenivå.

Behandling med «local infiltration analgesi» (LIA) medfører at pasientene kan mobiliseres operasjonsdagen (20). Via et kateter inn i operasjonsområdet gir sykepleieren påfyll av lokala- nalgetika til faste tider. Kateteret seponeres om morgenen første postoperative dag. Oversikt over smertebehandlingsprotokollen er vist i tabell 1 .

To til tre pasienter følger hverandre gjennom oppholdet og fungerer som støttespillere for hverandre. Pasientene utskrives fjerde postoperative dag, og videre opptrening foregår på et opptreningssenter eller med fysioterapi i hjemmekommunen.

I denne studien er begrepet pasientmedvirkning sentralt, da pasientene har rett til å delta i beslutninger vedrørende egen helse og behandling (21). Pasientmedvirkning bygger på autonomiprinsippet, og forutsetter at tilpasset informasjon er gitt, at pasienten har samtykkekompetanse, kan uttrykke konsistente valg og er fri fra ytre press $(22,23)$.

En studie (24) framhever at pasientmedvirkning består av følgende forhold: en etablert relasjon mellom sykepleier og pasient, overgivelse av makt og kontroll, delt informasjon og kunnskap, og en aktiv pasientdeltakelse i både intellektuelle og fysiske aktiviteter.

Hensikten med denne studien er å kartlegge hvordan sykepleierne samhandler med pasientene om den postoperative smertebehandlingen ved Joint Care, og videre belyse hvordan pasientmedvirkning kan fremmes.

TABELL 1: Utdrag fra smertebehandlingprotokollen for Joint Care (NN-helseforetak mai 2010).

\section{Preoperativt}

Peroperativt

Operasjonsdagen

Videre forløp

Adjuvant behandling
Kvelden før kl 20.00: Buprenorfin plaster 5 mcg/t og paracetamol 1 g per os. Operasjonsdagen: Paracetamol $1 \mathrm{~g}$ per os og ibuprofen $400 \mathrm{mg}$ per os.

Spinalanestesi : Fentanyl/ bupivacain.

Lokalanaestesi ( LIA): Ropivakain/adrenalinlsing (cold therapy).

Smerteregimet kontinueres med buprenorfin plaster, paracetamol per os og ibuprofen per os. Eventuelt: Oksykodon 5 mg per os og/eller Ketobemidon 2,5-5 mg iv.

Påfyll av ropivakain/adrenalin i LIA-kateter 4 timer etter operasjon.

Samme behandling som operasjonsdagen.

KL.08.00: påfyll av ropivakain/adrenalin i LIA-kateter, deretter seponeres kateteret. Eventuelt oppstart av oksykodon depot per os.

Isposer (cold therapy) legges på det opererte området etter trening med fysioterapi og ellers ved behov.

Hensikten er å kjøle ned og dempe hevelse.

TABELL 2: Intervjuguide

- Hvordan vil du beskrive pasientenes smerte- og aktivitetsnivå ved Joint Care?

- Hvilke intervensjoner/tiltak iverksettes for å lindre smerte?

- Hvordan kartlegger du pasientens smerteopplevelse?

- Hvordan vil du beskrive pasientenes deltakelse i sin egen smertebehandling?

- Hvordan erfarer du at smerteopplevelsen påvirker pasientens funksjonsnivå og/eller andre områder?

- Hvordan erfarer du sammenhengen mellom pasientens smerteopplevelse/smertehåndtering og f. eks: preoperativ informasjon, sammensetning av pasientgrupper, fysiske omgivelser, tidsramme/behandlingsforløp? Andre forhold?

- Hvordan erfarer du sammenhengen mellom pasientens smerteopplevelse/smertehåndtering og f.eks: alder, kjønn,

sosial bakgrunn, kunnskapsnivå, helsetilstand, tidligere smerteerfaring?

- Er det andre forhold du ønsker å utdype? 
Med samhandling forstår vi en mellommenneskelig relasjon hvor dialog og felles forståelse av målet er sentralt (25). I denne studien vil postoperative rutiner være retningsgivende for samhandlingen. Dette leder til følgende forskningsspørsmål:

1. Hvordan erfarer sykepleierne rutinene for smertebehandling og mobilisering?

2. Hvordan erfarer sykepleieren samhandlingen med pasienten?

\section{METODE}

Studien fulgte et kvalitativt beskrivende design (26) med semistrukturerte dybdeintervjuer $(27,28)$. I samarbeid med enhetsleder for ortopedisk sengepost ble det gjort et strategisk utvalg av informanter. Fem sykepleiere ble invitert og svarte ja til å delta. Førsteforfatter gjennomførte intervjuene på sykepleiernes arbeidssted. I intervjusituasjonen kom sykepleiernes beskrivelse og forståelse av egen praksis til uttrykk (28). Intervjuguiden er vist $\mathrm{i}$ tabell 2 . Førsteforfatter bekreftet utsagnene gjennom oppklarende spørsmål og kommentarer, og skrev notater etter hvert intervju i forhold til tid, sted, stemning, forstyrrelser og kvaliteten på samtalen (29). Det ble brukt lydbåndopptak, førsteforfatter transkriberte hvert intervju ordrett, og gjorde deretter en «spot-check» der et utdrag av transkriptet ble lest mens lydopptaket ble avspilt (30). (Se tabell 2.)

Førsteforfatter leste det samlede transkriptet flere ganger, og andreforfatter leste et utdrag. Forskningsspørsmålene og intervjuguiden dannet overskrifter for den videre grovsortering av datamaterialet. Alle sykepleierne ble sitert under hvert spørsmål, og ble merket med hvert sitt nummer og ulike tekstfarger. Meningsbærende enheter, de deler av teksten som gir innhold og sammenheng, ble merket med fet skrift. Det ble videre gjort en kondensering, en forkorting av teksten der unødige fyllord ble fjernet, samtidig som det sentrale innholdet ble bevart (31). Andreforfatter kontrollerte utdrag fra den kondenserte teksten og sammenliknet dette med transkriptet. Noen sitater ble stående i sin helhet for å kunne brukes som illustrasjoner på sykepleiernes erfaringer. De kondenserte meningsenheter ble gruppert under henholdsvis forskningsspørsmål 1 eller 2 . Kjernen i enhetene dannet utgangspunkt for beskrivende kategorier som gjenspeilet praksis (31). Det ble opprettet to kategorier under hvert forskningsspørsmål. Innholdet i kategoriene ble oppsummert, og den underliggende mening og røde tråd ble formulert som tema (31). Eksempler fra analysen er vist i tabell 3.

\section{ETISKE ASPEKTER}

Studien er godkjent av personvernombudet for forskning (32), og ivaretar krav til informert samtykke og konfidensialitet (33). Da det kun er tre helseforetak i Norge som praktiserer Joint Care, er det tatt særlig hensyn til anonymisering av informantene ved at sitater ikke er knyttet til ansiennitet eller funksjonsområder.

\section{FUNN \\ Bakgrunn}

Sykepleiere som deltok i studien hadde et ansiennitetsspenn fra halvannet til sju år ved den aktuelle sengeposten. Alle hadde regelmessig deltatt i postoperativ behandling ved Joint Care det siste året, og bidro med kliniske erfaringer. Tre av sykepleierne ivaretok også spesifikke ansvarsområder innen henholdsvis preoperativ informa-

TABELL 3: Fra forskningsspørsmål til tema

\begin{tabular}{|c|c|c|c|}
\hline Forskningsspørsmål & Eks. kondenserte meningsenheter & Kategorier & Tema \\
\hline \multirow[t]{2}{*}{$\begin{array}{l}\text { Hvordan erfarer } \\
\text { sykepleieren rutiner } \\
\text { for smertebehandling } \\
\text { og mobilisering? }\end{array}$} & $\begin{array}{l}\text { Pasientene får lokal smertelindring } \\
\text { gjennom et kateter. De fleste er oppe } \\
\text { av sengen operasjonsdagen. }\end{array}$ & Rutiner 1. postoperative døgn & $\begin{array}{l}\text { Inadekvat smerte- } \\
\text { behandling ved } \\
\text { mobilisering } \\
\text { 2. postoperative dag }\end{array}$ \\
\hline & $\begin{array}{l}\text { Sykepleierne rekker ikke alltid å gi } \\
\text { smertestillende før trening. }\end{array}$ & Rutiner 2.-4. postoperative døgn & \\
\hline \multirow[t]{2}{*}{$\begin{array}{l}\text { Hvordan erfarer } \\
\text { sykepleieren } \\
\text { samhandlingen } \\
\text { med pasienten? }\end{array}$} & $\begin{array}{l}\text { Pasientene er tilbakeholdne. Selv om } \\
\text { pasientene har smerter under aktivi- } \\
\text { tet må de ofte tilbys smertestillende. }\end{array}$ & $\begin{array}{l}\text { Pasientens deltakelse ismerte } \\
\text { behandling og mobilisering }\end{array}$ & $\begin{array}{l}\text { Eldre pasienter } \\
\text { er tilbakeholdne } \\
\text { med å rapportere } \\
\text { smerter }\end{array}$ \\
\hline & $\begin{array}{l}\text { Sykepleierne bruker tid på å forklare } \\
\text { nivåene i skalaen for pasientene. }\end{array}$ & $\begin{array}{l}\text { Bruk av NRS og verbale beskri- } \\
\text { velser }\end{array}$ & \\
\hline
\end{tabular}


sjon ved Joint Care, postoperativ smertebehandling, og innen fagutviklingsarbeid. Utvalgets variasjon, både $\mathrm{i}$ ansiennitet og ansvarsområder, bidro til å framskaffe ulike perspektiver og dybdekunnskaper.

Operasjonsdagen og første postoperative dag hadde sykepleiere ansvar for Joint Carepasientene, med tilsyn minst hver time. Fra andre postoperative dag kunne hjelpepleiere også ha pasientansvar, mens sykepleieren hadde ansvaret for medikamenthåndtering og andre sykepleieroppgaver.

\section{1) Hvordan erfarer sykeplei- erne rutinene for smertebe- handling og mobilisering?}

Sykepleierne erfarte at de aller fleste pasientene fulgte opptreningsprogrammet. De var uavhengige av hjelp til personlig hygiene og oppegående med krykker fjerde postoperative pasientene stelle seg på badet før frokost første postoperative dag. Sykepleierne erfarte at dette var vanskelig å gjennomføre, da de ofte ikke rakk å gi påfyll i LIAkateteret før morgenstellet. «De fleste pasientene er ikke så kvikke at de klarer å gå på badet før de har fått påfyll i LIA-kateteret, så da er det ofte at de setter seg på sengekanten med et vaskefat og får frokost på senga.»

LIA-kateteret ble seponert om morgenen første postoperative dag rett etter at påfyll av lokalanalgetika ble gitt. Sykepleierne fortalte at mange pasienter rapporterte økende smerter den påfølgende natt og dag, etter at effekten av lokalanalgetika hadde gått ut. Smertekartlegging viste ofte NRS-verdi på 6-7 i hvile, og sykepleierne beskrev dette som en «nedtur» for pasientene.

Noen av sykepleierne erfarte at smerte under trening ofte ble rapportert fra fysioterapeuten,

\section{Noen ligger med synlige tegn på smerte ... de gråter og har det ordentlig vondt, mens andre er det ikke så lett å se det på.}

dag. Et fåtall ble av ulike helsemessige årsaker overført til tradisjonelt behandlingsforløp postoperativt.

Fram til første postoperative dag erfarte sykepleierne at de på en effektiv og kontrollert måte kunne behandle pasientens smerte ved hjelp av LIA-kateter. Smerte ble registrert ved hjelp av NRS, hvor de fleste pasientene anga $0-1$ i hvile og 3-5 i aktivitet. Om kvelden operasjonsdagen klarte de fleste pasienter å gå noen skritt eller stå ved senga, mens noen ventet til første postoperative dag på grunn av smerte, kvalme eller svimmelhet.

Ifølge retningslinjene skulle og sykepleierne måtte gi ekstra smertestillende midt i treningsøkten. Andre erfarte at de ikke fikk beskjed før etter treningen. «Det er ikke alltid samsvar mellom det pasienten sier til oss og det som rapporteres på skjemaene hos fysioterapeuten. Der står det veldig ofte at pasienten har hatt sterke smerter, og så har vi en annen opplevelse fordi vi ikke har fått noen forespørsel, eller vi har ikke forstått at pasienten har vondt».

Sykepleierne hadde ikke klare rutiner for å gi smertestillende $\mathrm{i}$ hensiktsmessig tid før trening, og savnet bedre dialog med fysioterapeuten.

\section{2) Hvordan erfarer sykepleieren samhandlingen med pasienten?}

Sykepleierne fortalte at pasienter over 65 år ofte var tilbakeholdne med å rapportere smerter og be om smertestillende. "Noen ligger med synlige tegn på smerte ... de gråter og har det ordentlig vondt, mens andre er det ikke så lett å se det på ... så man må jo bare spørre hvordan de har det». Sykepleierne måtte ofte tilby analgetika og minne pasienten om å rapportere smerte. Ifølge en av sykepleiere var pasientens tilbakeholdenhet knyttet til en misoppfatning av at de ikke skulle be om mer enn de faste medikamentene.

En sykepleier beskrev pasientene slik: «De aller fleste sier: <jeg tar det du kommer med, eller ‘bare jeg får noe, så er det samme hva»». Mange har hatt mye smerter i forkant og sier at «den vondten her den må jeg bare klare`... for de vet at det blir til det bedre».

Sykepleierne framhevet samtidig at dersom pasientene ikke hadde ønskelig effekt av det gitte medikamentet, spesielt ved bruk av LIA-kateter, så var de tydelige på å rapportere dette. Noen av sykepleierne erfarte at de fleste pasientene var aktive og ba om smertestillende, spesielt før trening. De mente dette var en konsekvens av preoperativ undervisning, og trakk fram at pasientene kunne si: «De sa jo det at det kommer til å gjøre vondt ... OK, jeg spør etter mer smertestillende.» Pasientens kunnskap om at både bevegelse og rett hvilestilling fremmer smertelindring, samt at protesen ikke løsner ved belastning, ble også framhevet som sentralt.

Studien viste at NRS-målinger ble systematisk gjennomført ved påfyll i LIA-kateteret. I det videre forløp gjennomførte flere av syke- 
pleierne NRS-målinger kun ved behovsmedisinering. Flere av sykepleierne framhevet at de ofte var usikre på om pasienten forsto bruk av skalaen, og hvordan de skulle tolke pasientens angitte NRS-verdi. Enkelte erfarte at det var vanskelig å tro på pasientens smerteopplevelse hvis de anga NRS-verdi på mellom 6 og $8, \mathrm{og}$ samtidig kunne sitte å lese, spise, le, snakke, gå i korridoren, eller ha normalt blodtrykk og puls. Andre sykepleiere poengterte at dialog omkring pasientens høye NRS-verdi var viktig, da noen kunne velge fysiske avledningsstrategier, mens andre pasienter ikke klarte å tenke på annet enn smerten. Ved NRS-verdier på mellom 8 og 10 oppfordret en av sykepleierne alltid pasienten til å beskrive smertens karakter i tillegg. Ved beskrivelser som «verking i såret», «stikkende smerter», "som om foten vrenges», eller «som å få en tykk kniv vridd rundt», vurderte sykepleieren at NRS-verdien samsvarte med smertens styrke. Slike beskrivelser tolket sykepleieren som sterkere smerte enn for eksempel «murring».

Flere av sykepleierne var enige om viktigheten av å forklare NRS-skalaen for pasientene: «Nå har du klart å spise mat, nå har du klart å gå til stua ... da tenker jeg at NRS er under 3.... Det ser ikke ut som du trenger mer smertestillende ...?»... «Når NRS øker fra 3 til 4 er det vanskelig for deg å sitte i ro, og ved 5 er det ordentlig ubehagelig, ... da er du virkelig urolig»... «Når du er på 8 så har du egentlig lyst å være en helt annen plass enn ute å gå ..., da har du ikke lyst å bevege deg noe i det hele tatt».

Sykepleierne erfarte at spesielt eldre pasienter kunne ha problemer med å tallfeste sin smerteopplevelse, og ved sterke smerter kunne pasientene bli ukonsentrerte. Sykepleierne framhevet at uansett alder så var det ikke lett for pasientene å angi et tall som sto i relasjon til «den verst tenkelige smerte». En av sykepleierne poengterte at selv om det kan være vanskelig å tolke de ulike NRS-nivåene pasienten angir, er skalaen et nyttig hjelpemiddel til å evaluere effekt av analgetika. Spesielt etter påfyll i LIA-kateteret erfarte sykepleieren at pasientene anga en lavere NRS-verdi.

\section{DISKUSJON}

Sykepleierne framhevet at pasientene ble tidlig mobilisert og var aktive i treningen. Det ble framhevet at bruk av LIA-kateter ga god kontroll over smertebehandlingen. Etter overgang til peroral smertebehandling rapporterte ofte fysioterapeutene at pasientene hadde smerter under trening, samtidig som sykepleierne savnet bedre dialog med fysioterapeutene om smertebehandlingen. Sykepleierne beskrev pasientene generelt som aktive til å rapportere manglende effekt av analgetika, men mange eldre kunne være tilbakeholdne. NRS ble aktivt brukt i smertekartleggingen, men sykepleierne erfarte at pasientens kunnskaper om skalaen varierte.

\section{Smertebehandling og mobilisering}

Sykepleierne erfarte at bruk av LIA-kateter bidro til at de fleste pasienter var oppe av sengen operasjonsdagen. Tidligere studier viser at LIA-kateteret har effekt på tidlig mobilisering etter hofteog kneprotesekirurgi $(34,35)$. Et av prinsippene ved Joint Care er å begrense bruk av smerte- og urinkatetre, og ved overgangen til perorale administrasjonsformer erfarte sykepleierne at pasientene ofte rapporterte sterke smerter.
Dette kan tyde på at LIA-kateteret ble seponert for tidlig, eller at sykepleierne hadde uklare rutiner for å forebygge smerter ved hjelp av perorale medikamenter.

Et av kriteriene for pasientmedvirkning er aktiv deltakelse i fysiske aktiviteter (24). Tidligere studier framhever at trening er avgiørende for leddets bevegelighet, og forebygger postoperative komplikasjoner etter protesekirurgi (2). Denne studien belyser at trening med fysioterapeut ofte ble avbrutt på grunn av smerter. Sykepleierne trakk fram at de ikke visste tidspunkt for trening, og dermed ikke rakk å gi smertestillende i forkant. Dette understreker viktigheten av et tett samarbeid mellom sykepleiere og fysioterapeuter, og at pasienten også inkluderes i planlegging av treningen. Hensikten med pasientens deltakelse i postoperativ smertebehandling er at pasienter og helsearbeidere skal jobbe sammen mot et ønsket resultat (36). Joint Care innebærer et intensivt mobiliseringsprogram, og dette forutsetter at treningsøktene er effektive.

\section{Den tilbakeholdne pasienten}

Overgivelse av makt og kontroll inngår i kriteriene for pasientmedvirkning (24). I hvilken grad pasientene opplever dette viser ikke denne studien. Sykepleierne fortalte at pasientene hadde ansvar for å rapportere smerte og ble dermed gitt en viss kontroll, men samtidig forutsetter dette at pasienten vet hva som er et akseptabelt smertenivå og når de kan melde fra. Sykepleierne beskrev en mulig underrapportering av smerte hos eldre med langvarige smertetilstander, og at de måtte påminne pasienten å be om smertestillende. Tidligere forskning viser at ortopediske pasienter ofte har en baken- 
forliggende smertehistorie som kan øke kompleksiteten i den postoperative smertebehandlingen (3). Generelt er hyperalgesi framtredende etter langvarige smertetilstander, og innebærer økt smerteopplevelse ved ulike smertestimuli (37). En studie viser at eldre pasienter over 65 år opplever intensiteten i akutte smerter i like stor grad som yngre (38). Dette gir holdepunkter for at den eldre pasientgruppen i Joint Care kan ha sterke smerter selv om de ikke uttrykker den verbalt.

\section{De sa jo det at det kommer til å gjore vondt ... OK, jeg spor etter mer smertestillende.}

Sammenhengen mellom alder og manglende smerterapportering kan forklares på bakgrunn av de eldres underdanige holdning til helsevesenet (39), og at pasienten knytter mening til den akutte smerten (37). Eldre forbinder ofte smerte med en naturlig del av alderdommen og er ofte skeptiske til bruk av medikamenter (40). Sykepleierens kunnskap om den eldres smertefysiologi og smerteuttrykk er sentralt for å forstå hvilke vurderinger og tiltak som bør iverksettes. En studie framhever at både motivasjon og adekvat smertebehandling er forutsetninger for å delta i et akselerert pasientforløp (41). Den preoperative informasjon som er gitt kan dermed ikke erstatte sykepleierens ansvar for å smertelindre pasienten, og spesielt med tanke på at eldre kan ha en passiv tilnærming.

\section{Kunnskap om smertekartlegging}

Pasientmedvirkning forutsetter delt informasjon og kunnskap mellom sykepleier og pasient (24), og tilpasset informasjon er en forutsetning for pasientens autonomi
(42). Tidligere studier viser at adekvat informasjon øker pasientens evne til å ta avgjørelser og valg på bakgrunn av kunnskap (7).

Studien viste at informasjon om bruk av NRS og om viktigheten av smerterapportering ble gitt preoperativt, men sykepleierne hadde ingen felles rutiner for hvordan de skulle gjenta eller oppklare denne informasjonen postoperativt.

En studie framhever at pasienter har ulike mestringsstrategier for hvor mye og hvor detaljert

informasjon de klarer å absorbere, og de kan sitte igjen med en helt annen forestilling enn det som er forventet (16). Dette viser betydningen av å gjenta informasjon postoperativt om hvordan og når pasienten skal rapportere smerte.

Tidligere forskning viser at aktuelle barrierer for effektiv smertebehandling ligger i misoppfatninger og holdninger hos både pasienter og sykepleiere (15). Dette samsvarer med denne studien som pekte på at misoppfatninger også hos sykepleieren, var en mulig barriere for effektiv smertebehandling. Når sykepleieren betvilte pasientens angitte NRS ble det trolig ikke tatt hensyn til de fysiologiske forandringene som følger den akutte smerte (43), og til de mestringsstrategier pasientene utvikler ved langvarige smertetilstander (40). Utfordringer med å vurdere hva postoperative pasienter legger i en NRS-verdi på 6-8, og en usikkerhet om at pasienten forstår bruken av NRS, er også belyst i en nyere studie (44).

Studien viste også at sykepleierne la vekt på å forklare hvor- dan skalaen kunne anvendes og tolkes, og brukte dialog og pasientens verbale beskrivelser som et supplement til NRS. Dette støttes av studier som påpeker at endimensjonale smerteskalaer kun viser smertens intensitet og ikke dens opplevelsesdimensjon $(45,46)$. Sykepleiernes skepsis til bruk av smertekartleggingsverktøy er beskrevet i en studie der bruk av NRS er beskrevet som subjektivt, upresist, vanskelige å relatere til andre, og at pasienter ikke vet hvordan de skal gradere smerten (47). For å fremme pasientmedvirkning er det derfor sentralt at sykepleier og pasient sammen avklarer en felles forståelse av hvordan smerten kan kartlegges (48).

\section{Styrke og begrensning}

Studien tar utgangspunkt i sykepleiernes erfaringer. I hvilken grad dette representerer pasientenes opplevelser er derfor usikkert. Data fra pasienter ville gitt et mer nyansert perspektiv på begrepet pasientmedvirkning. Studiens utvalg var lite, men intervjuene ga en dybdeforståelse av hvordan sykepleierne erfarte nye behandlingsmetoder.

\section{KONKLUSJON}

Studien belyser at akselererte pasientforløp ved protesekirurgi innebærer nye roller med krav til en aktiv kunnskapsoverføring fra sykepleier til pasient. For videre forskning anbefales kvalitative studier som kartlegger pasienters opplevelse av medvirkning ved akselererte pasientforløp, samt kvantitative studier som kartlegger sykepleieres erfaringer med å anvende smertekartleggingsverktøy.

En stor takk går til sykepleierne som deltok i studien, og til sykepleieledelsen ved avdelingen. 


\section{REFERANSER}

1. McHugh GA, Luker KA. Influences on individuals with osteoarthritis in deciding to undergo a hip or knee joint replacement: A qualitative study. Disabil Rehabil 2009; 31:1257-66.

2. Horlocker T. Pain Management in Total Joint Arthroplasty: A Historical review. Orthopedics 2010;23:14-19

3. Pasero C, \& McCaffery M. Orthopaedic Postoperative Pain Management. J Perianesth Nurs. 2007:22:160-74.

4. Biomet. Rapid recovery principles. http://www.rapid-recovery.co.uk/healthcare-providers/Principle (Nedlastet 17.10.12)

5. Gordon D, Malhas A, Goubran A, Subramanian $\mathrm{P}$, Messer $\mathrm{C}$ \& Houlihan-Burne D. Implementing the Rapid Recovery Program in primary hip and knee arthroplasty in a UK state run hospital. EJOST 2010;21:151-158.

6. Berend, K, Lombardi, A J, \& Mallory, T. Rapid recovery protocol for peri-operative care of total hip and total knee. Surg Technol Int. 2004:13:239-247

7. Walker, J. What is the effect of preoperative information on patient satisfaction? BJN 2007:16:27-32

8. White, P F, \& Kehlet, H. Improving postoperative pain management: what are the unresolved issues? Anesthesiology 2010;112:220-225

9. Kehlet, H, \& Wilmore, D W. Evidencebased surgical care and the evolution of fast- track surgery. Ann surg. 2008:248:189-198.

10. Antrobus, JD \& Bryson, GL. Enhanced recovery for arthroplasty: good for the patient or good for the hospital? J Can. Anesth. 2011:58:891-896.

11. Husted, H, Solgaard, S, Hansen, T, Søballe, K, \& Kehlet, H. Care principles at four fast-track arthroplasty departments in Denmark. Ugeskr Laeger 2010;57:41-66. 12. Larsen, K, Hansen, TB, \& Søballe, K. Hip arthroplasty patients benefit from accelerated perioperative care and rehabilitation: a quasi-experimental study of 98 patients. Acta Orthop. 2008;79:624-630.

13. Larsen, K, Hvass, KE, Hansen, TB, Thomsen, PB, \& Søballe, K. Effectiveness of accelerated perioperative care and rehabilitation intervention compared to current intervention after hip and knee arthroplasty. A before-after trial of 247 patients with a 3- month follow-up. BMC Musculoskelet Disord. 2008;9:1-9.

14. Husted, H, Holm, G, \& Sonne-Holm, S. Reduced length of hospital stay after total hip and knee arthroplasty without increased utilization of other resources. Ugeskr Laeger 2004;166: 3194-3197.

15. Bell, L, \& Duffy, A. Pain assessment and management in surgical nursing: a literature review. BJN 2009;18:153-156. 16. Kruzik, N. Benefits of preoperative education for adult elective surgery patients. AORN J 2009; 90:381-387 17. International Association for the study of pain. http://www.iasp-pain.org/AM/ Template. $\mathrm{cfm}$ ?Section $=$ Home \&Template $=$ CM/ContentDisplay. cfm\&ContentID=12173 (Nedlastet 17.10.12)

18. Noble, B, Clark, D, Meldrum, M, Have, HT, Seymour, J, Winslow, $M$, et al. The measurement of pain, 1945-2000. J Pain Symptom Manag 2005;29:14-21.

19. Breivik, H, Borchgrevink, PC, Allen, SM, Rosseland, LA, Romundstad, L, Hals, EKB, et al. Assessment of pain. Br J Anaesth. 2008;101:17-24.

20. Kerr, DR, \& Kohan, L. Local infiltration analgesia: a technique for the control of acute postoperative pain following knee and hip surgery: a case study of 325 patients. Acta Orthop 2008; 79: 174-83.

21. Lovdata. Pasient- og brukerrettighetsloven (1999). http://www.lovdata.no/all/ nl-19990702-063.html (Nedlastet 17.10.12) 22. Slettebø, А, \& Nortvedt, P. Etikk for helsefagene. Oslo: Gyldendal akademisk, 2006

23. Norsk Sykepleierforbund. Yrkesetiske retningslinjer for sykepleiere. https:// www.sykepleierforbundet.no/ikbViewer/ Content/785285/NSF-263428-v1-YERhefte pdf.pdf (Nedlastet 17.10.12)

24. Sahlsten, MJ, Larsson, IE, Sjostrom, B, \& Plos, K A. (2008). An analysis of the concept of patient participation. Nurs Forum 2008; 43: 2-11.

25. Peplau, H. Interpersonal Relations in Nursing-A conceptual framework of Reference for Psycodynamic Nursing. New York: Springer Publishing Company, 1991 26. Sandelowski, M. Whatever happened to qualitative description? Res Nurs Health. 2000; 23: 334-40

27. Kelly, S. The Sage handbook of qualitative methods in health research. In $\mathrm{R}$. ingwall R. De Vries \& I. Bourgeault (Eds.), London: Sage, 2010: XXV

28. Kvale S, \& Brinkmann, S. Interview: introduktion til et håndværk. København: Hans Reitzel, 2009

29. Fagermoen, MS. Kvalitative studier og kvalitetskriterier. Norsk tidsskrift for Sykepleieforskning 2005;7:40-54

30. MacLean, L, Meyer, M, \& Estable, A. Improving Accuracy og Transcrips in Qualitative Research. Qual Health Res. 2004;14:113-23.

31. Graneheim, UH, \& Lundman, B. Qualitative content analysis in nursing research: concepts, presdures and measures to achieve trustworthiness. Nurse Educ Today 2003;24: 105-12.

32. Norsk samfunnsvitenskapelige datatjenester (NSD). http://www.nsd.uib.no/ (Nedlastet 17.10.12)

33. Fontana, A,\& Frey, J. The Sage handbook of qualitative research. In: Densin, NK \& Lincoln, S. (Eds.) Thousand Oaks, Calif. Sage, 2005

34. Andersen, K, Bak, M, Christensen, B,
Harazuk, J, Pedersen, N, \& Søballe, K. A randomized, controlled trial comparing local infiltration analgesia with epidural infusion for total knee arthroplasty. Acta Orthop. 2010; 81: 606-10.

35. Sharma, V, Morgan, P, \& Cheng, E. Factors Influencing early Rehabilitation After THA. Clin Orthop Relat Res. 2009;467:1400-11

36. Haig, C. Editorial: This might hurt ... a reflection on pain management in the $21 \mathrm{st}$ century. J Clin Nurs. 2008;17:1961-2

37. Stubhaug, A, \& Ljoså, T. Hva er smerte? I: Rustøen, T\& Wahl, AK. Ulike tekster om smerte. Fra nocisepsjon til livskvalitet. Oslo: Gyldendal akademisk, 2008.

38. Prowse, M. Postoperative pain in older people: a review of the literature. J Clin Nurs. 2007;16:84-97.

39. Hansson, E, Fridlund, B, \& Hallström, I. Effects of a Quality Improvement Program in Acute Care Evaluated by Patients, Nurses, and Physicians. Pain Manag Nurs. 2006,7:93-108.

40. Torvik, K, \& Bjøro, K. Smerte hos eldre. I: Rustøen, T\& Wahl, AK. Ulike tekster om smerte. Fra nocisepsjon til livskvalitet. Oslo: Gyldendal akademisk, 2008.

41. Ranawat, A, \& Ranawat, C. Pain Management and Accelerated Rehabilitation for Total Hip and Total Knee Arthroplasty. J Arthroplasty 2007; 22: 12-14

42. Pedersen, R, Hoffmann, B, Mangset, M. Pasientautonomi og informert samtykke i klinisk arbeid. Tidsskr Nor Laegeforen. 2007:127:1644-47

43. McCaffery, M, \& Beebe, A. Smerter: lærebok for helsepersonell. Oslo: Gyldendal Norsk forlag, 2001.

44. Leegaard M, Huseby $Y$, Berge AW, Rustøen T. Hvilke kunnskaper trenger sykepleiere for å hjelpe pasienter til å håndtere smerter etter hjertekirurgi? Sykepleien Forskning 2011; 6: 254-261

45. Rolfsson, H. Fallgropar vid mätning av smärta. Visuella analogskalan som smärskattningsmetod ifrågasatt. Läkartidningen 2009;106:591-3.

46. Gordon, DB, Dahl, JL, Miaskowski, C, McCarberg, B, Todd, KH, Paice, JA et al. American Pain Society Recommendations for Improving the Quality of Acute and Cancer Pain Management: American Pain Society Quality of Care Task Force. Arch Intern Med. 2005: 165: 1574-80.

47. Young, J, Horton, F, \& Davidhizar, R. Nursing attitudes and beliefs in pain assessment and management. J Adv Nurs. 2006:53:412-21

48. Manias, E, Bucknall, T, \& Botti, M. Assessment of patient pain in the postoperative context. West J Nurs Res. 2004; 26: 751-69

Les kommentaren på side $388 \quad \boldsymbol{}$ 